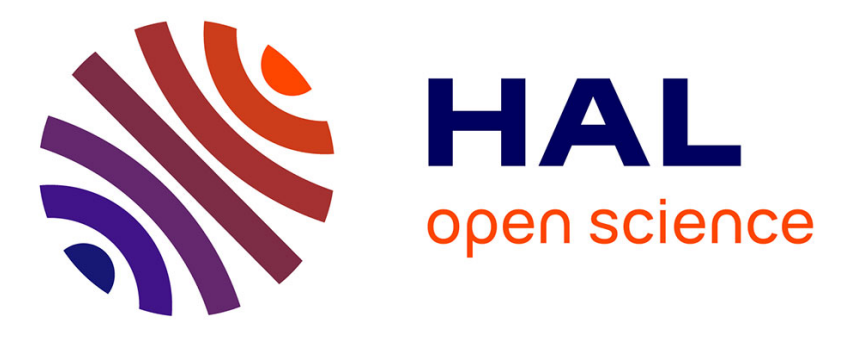

\title{
Distributed UI on Interactive tabletops: issues and context model
}

Sébastien Kubicki, Sophie Lepreux, Christophe Kolski

\section{To cite this version:}

Sébastien Kubicki, Sophie Lepreux, Christophe Kolski. Distributed UI on Interactive tabletops: issues and context model. Distributed User Interfaces: Collaboration and Usability, pp.27-38, 2013, 978-14471-5498-3. 10.1007/978-1-4471-5499-0_3 . hal-01103707

\section{HAL Id: hal-01103707 https://hal.science/hal-01103707}

Submitted on 15 Jan 2015

HAL is a multi-disciplinary open access archive for the deposit and dissemination of scientific research documents, whether they are published or not. The documents may come from teaching and research institutions in France or abroad, or from public or private research centers.
L'archive ouverte pluridisciplinaire HAL, est destinée au dépôt et à la diffusion de documents scientifiques de niveau recherche, publiés ou non, émanant des établissements d'enseignement et de recherche français ou étrangers, des laboratoires publics ou privés. 


\title{
Distributed User Interfaces: Collaboration and Usability
}

\author{
Distributed UI on Interactive tabletops: issues and \\ context model
}

\author{
Sébastien Kubicki $^{(1)}$, Sophie Lepreux ${ }^{(2)}$, Christophe Kolski ${ }^{(2)}$ \\ ${ }^{(1)}$ Lab-STICC UMR6285 / UBO / ENIB \\ European Center for Virtual Reality \\ Technopôle Brest-Iroise, F-29280 Plouzané, France \\ sebastien.kubicki@enib.fr \\ ${ }^{(2)}$ Université Lille Nord de France, F-59000 Lille, France \\ UVHC, LAMIH, F-59313, Valenciennes, France \\ CNRS, UMR8201, F-59313, Valenciennes, France \\ \{firstname.name\}@univ-valenciennes.fr
}

\begin{abstract}
The User Interface distribution can also be applied on interactive tabletops which are connected and more or less remote. This distribution raises issues which concern collaboration (how to distribute the UI to collaborate?); besides, concerning the tangible interaction: which role and appearance (tangible or virtual) must have the objects? In this chapter we describe an extended context model in order to take into account both interactions on a single interactive tabletop and interactions which are distributed and collaborative. The model proposed can, from our point of view, be used to make sure that the usability of the interaction is guaranteed. Indeed, it is essential to know the interaction configuration in order to ensure the usability of the system. The model suggested is illustrated in a case study integrating collaboration and UI distribution. A conclusion gives the limits of the article before a presentation of prospects.
\end{abstract}

\section{INTRODUCTION}

In a world in which everything and everybody are connected, it is possible to envisage connecting different platforms in order to carry out remote collaborations [17][22][5][21] (see also the chapters written by Garrido Navarro and his collegues, Rädle and his collegues, Harboe and his collegues in this book). Our work concentrates on the connection of interactive tabletops on which the users interact 
using tangible objects. There are few works in existence relating to connected tables. Very often, some complementary devices are introduced, such as in work of Yamashita et al. [24] which adds a videoconferencing system in order to support collaboration. In our work, we propose the use of one or several tables and some tangible objects in order to support interaction and collaboration. In [18], collaboration scenarios were presented according to different configurations (type of source platform and target platform, distribution strategy (master/slave or autonomous entities), UI distribution type (complete/partial), collaboration type (synchronous/asynchronous)). As suggested in Figure 1, in case of inter-connected tabletops, problematics concerning centralized distribution of UI, as well as network of DUI are various; for instance: how to connect such interaction supports? How to duplicate and extract information? etc. [18]. Afterwards, in [17], a concept of tangible objects called Tangigets is defined and illustrated, making it possible to support distant collaboration between a tangible interactive tabletop and other surfaces. Considering that the context could be a means to ensure the system usability [25], we think that it is interesting to take the context into account in order to try to propose usable surfaces.

In this article we propose to use the context model suggested by Kubicki et al. [11][13], which we widened so as to integrate the specificities of interactive tabletops in order then to widen it even further to integrate distribution characteristics. The following section of the article introduces the TangiSense interactive tabletop as well as the architecture which enables it to manage distribution. Then, we present the proposed context model. An application of this model is then illustrated before concluding and proposing research prospects. 
- Centralized distribution of UI: one "master" tabletop and "slave" platforms

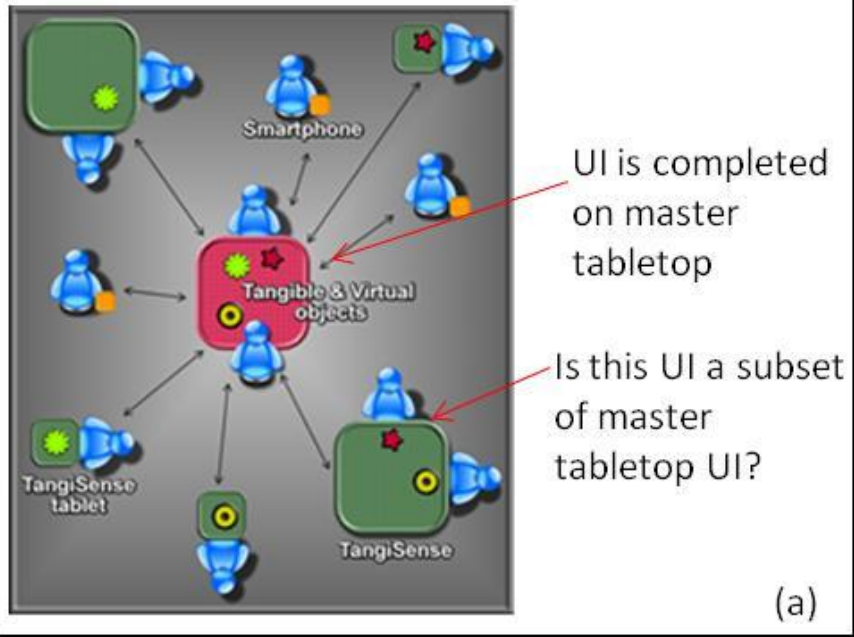

- Network of DUI: autonomous platforms

$\mathrm{UI}=\mathrm{f1}(\mathrm{UI} 1)+\mathrm{f} 2(\mathrm{UI2})+\mathrm{f} 3$ (UI3)

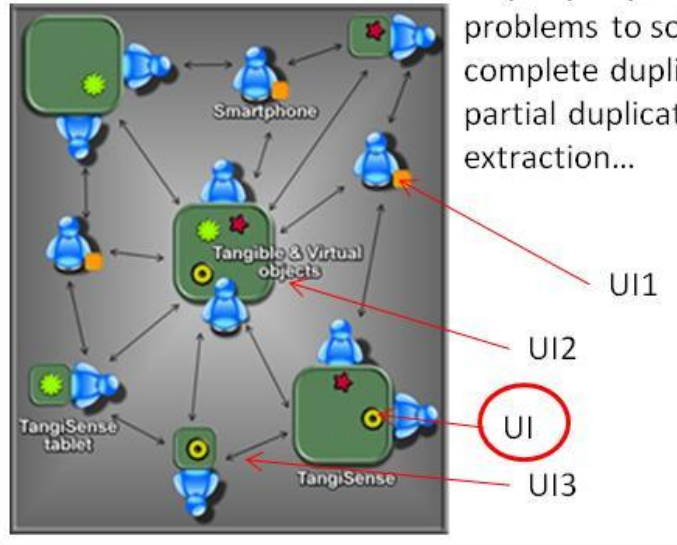

Figure 1. Problematics concerning (a) centralized distribution of UI, (b) network of DUI 


\section{FROM TANGISENSE INTERACTIVE TABLETOP TO DISTRIBUTED SURFACES}

This section aims to give a brief presentation of the support of our work which is the TangiSense interactive tabletop. This table has the characteristic of not being tactile, unlike the majority of interactive tabletops present on the market or in the scientific literature. It proposes a direct interaction via tangible objects. Table 1 presents eight different interactive tabletops, each one using a different capture technology.

It shows that each capture technology has its own characteristics. That is why the current interactive tabletops combine technologies. For more information, see Kubicki et al. [12].

Table 1. Five interactive tabletops using different capture technologies

\begin{tabular}{|c|c|c|c|c|}
\hline $\begin{array}{c}\text { Capture } \\
\text { technology }\end{array}$ & $\begin{array}{c}\text { Representative } \\
\text { example }\end{array}$ & $\begin{array}{c}\text { User } \\
\text { distinction }\end{array}$ & $\begin{array}{c}\text { Object } \\
\text { detection }\end{array}$ & $\begin{array}{c}\text { Object } \\
\text { overlay }\end{array}$ \\
\hline Capacitance & DiamondTouch [4] & Yes & No & No \\
\hline Rear DI & ReacTable [10] & No & Yes & No \\
\hline Webcam & Blip-Tronic 3000 [2] & No & Yes & No \\
\hline Fiber optical / DSI & Magets [23] & No & Yes & No \\
\hline PixelSense & Surface 2.0 [8] & No & Yes & No \\
\hline Touchscreen & eLabBench [9] & No & Yes & No \\
\hline Magnetic & Actuated Workbench [19] & No & Yes & No \\
\hline RFID & TangiSense [12] & Yes & Yes & Yes \\
\hline
\end{tabular}

The first part of this section presents the table while the second one presents the software architecture adopted to support the collaboration and the distribution between surfaces. 


\section{The TangiSense Interactive tabletop}

The TangiSense interactive tabletop is a prototype which uses RFID technology in order to communicate with tangible objects (equipped with RFID tag(s)). One tile of RFID reading which composes the table is shown in Figure 2(a). It was designed by the RFIdées ${ }^{1}$ company. For the users, the tabletop looks like a traditional table, because it is a similar size and texture (glass) to a table for everyday use (e.g. due to the technology employed, the users can place their hands on the table without interfering with the system). However, the tabletop has communication capacities via LEDs on its surface which make it possible to display texts (in low resolution) or to define zones (Figure 2(b)).

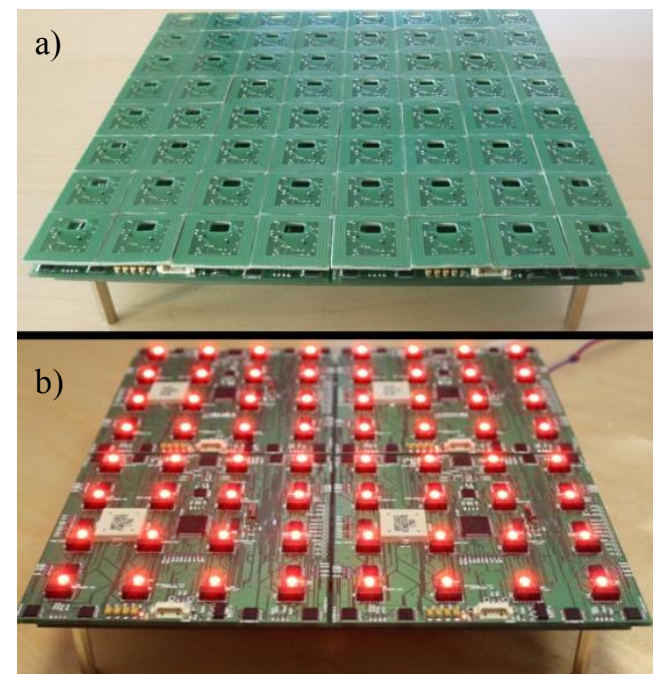

Figure 2. Tiles composing the tabletop in its first versions

It is possible, according to the applications, to use an external video projector in order to provide a finer grained display and to project directly on tabletop. The tabletop detects the RFID tagged objects and reacts according to them. Moreover, RFID tags offer the possibility to track objects, to store data into objects or to superimpose objects. In order to support the remote collaboration, particular objects, named Tangigets, were defined [17]. Details on the technical aspects of the table

\footnotetext{
${ }^{1}$ www.rfidees.fr
} 
can be found in [15]. A photograph of the table in an experimentation situation with several users is shown in Figure 3.

In its last evolution, TangiSense integrates directly a screen instead of LEDs.

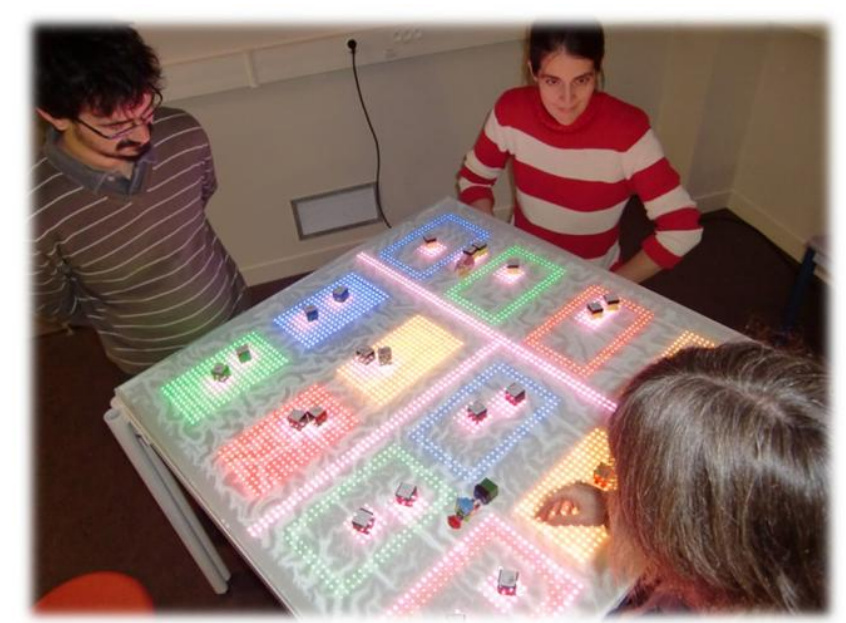

Figure 3. TangiSense, its objects and users during experimentation

\section{Architecture dedicated to distributed interaction}

The software aspects were initially defined for a single table, i.e. even if tables were physically connected, no interaction was envisaged with other platforms (the initial architecture is presented in Kubicki et al. [15]). From now on, the table architecture has evolved in order to be able to connect several tables and even several platforms, and so allow distribution [6] [11] [16]. This architecture Figure 4 is based on a Multi-Agent System (MAS) which will make it possible to integrate the context adaptation rules. The architecture is fully described in [6] and allows us to consider new distributed interactions in various contexts. 


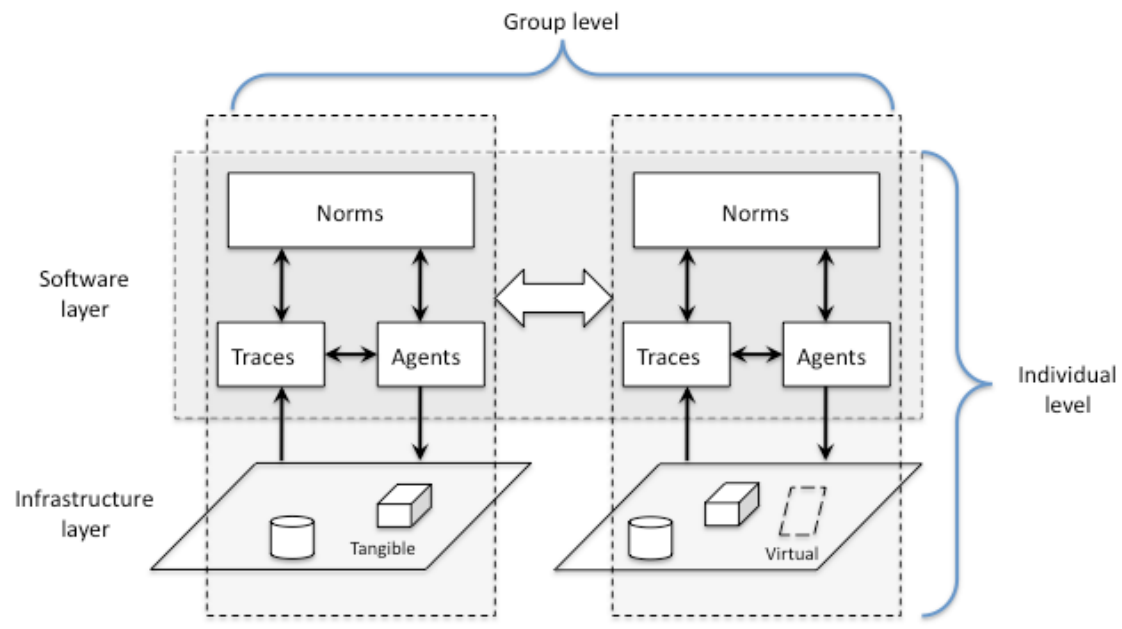

Figure 4. Functional architecture of TangiSense [6] (case of tables in interaction)

\section{PROPOSITION OF CONTEXT INTERACTION MODEL TO SUPPORT THE DISTRIBUTION}

Context-aware computing [20] appeared along with mobile platforms in order to adapt the applications to these new more restricted devices. In these contexts the user was alone on the platform but could switch from one platform to another (in general only one at the same time) ${ }^{2}$. Since then, many definitions and evolutions have covered the concept of context awareness. However, we chose to base our work on the Calvary et al. [3] proposal which defines the context as a triplet $<$ User, Platform, Environment $>$. From this triplet and a set of definitions from the state of the art, we proposed a context model [13]. This model was enriched to take into account the specificities of the interactive tabletops [11].

From a User point of view (Figure 5), the most important modification in comparison to the other platforms is the cardinality between User and Platform. Indeed, the interactive tabletops make it possible to work with several users

\footnotetext{
${ }^{2}$ However some works such as those of Grolaux et al. [7] are proposed on interface distribution between two types of platform.
} 
around their surface. The Location of the user relating to the platform is very important and influences the platform (display) itself. Indeed, the context will not be the same if the user position is on one side of the table (e.g. East) or on the opposite side (e.g. West). User posture, sitting or standing, is also important. Finally the interaction style is Post-WIMP and corresponds to competences in the use of tactile technology which can be multiTouch (tactile interactions), or in the use of objects (tangible interaction). The users who are collaborating together can have a social link which will influence their collaboration (parents/children, manager/employee, husband/wife, etc). It would also be necessary to specify which of the tasks are collaborative. It may only be a few of them (partial distribution) or all of them (full distribution). Problems appear concerning the distribution of the users distributed on tabletops: how to communicate, synchronize the tasks, collaborate? Some particular objects have to be defined to solve such problems [17].

Legend:

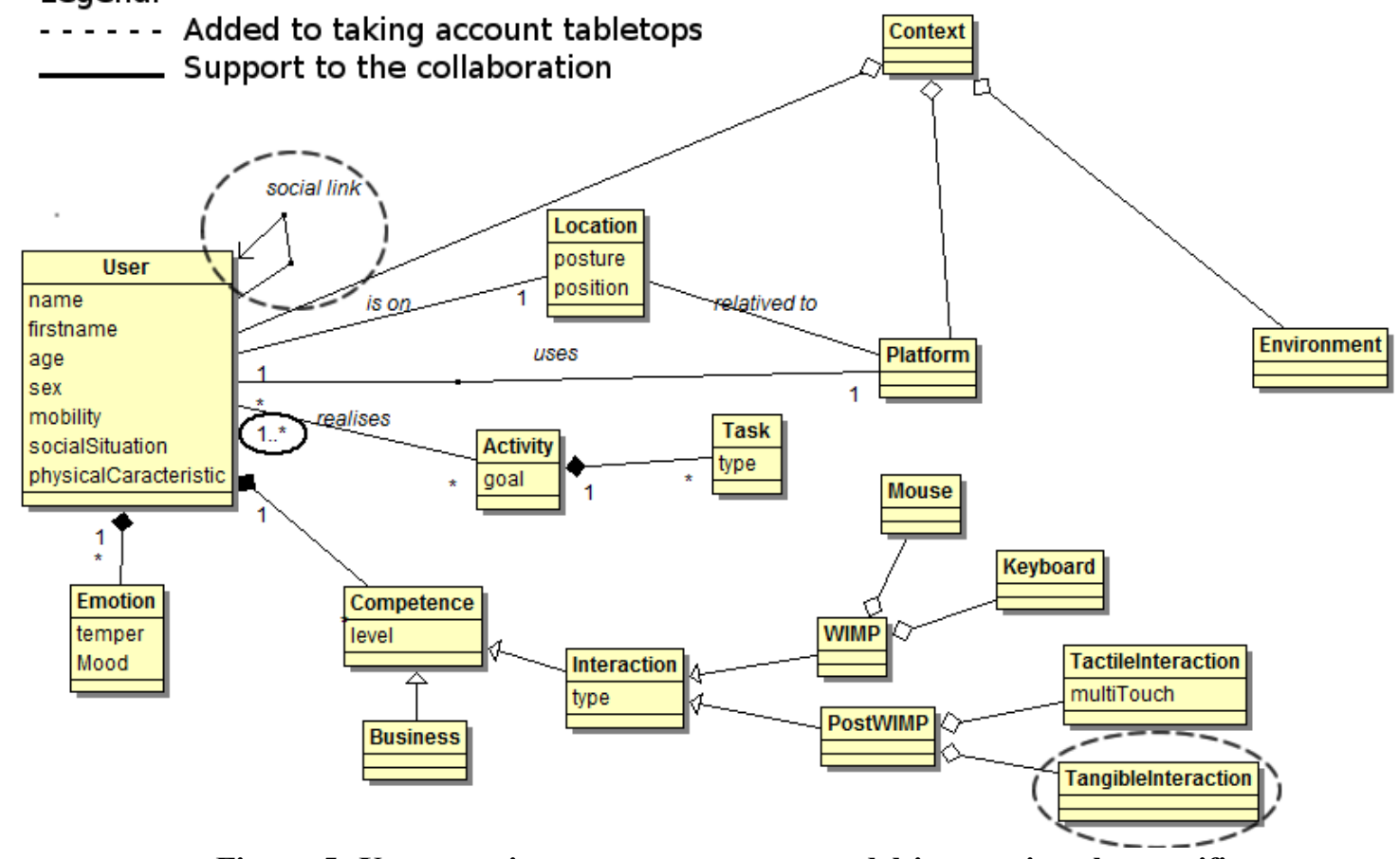

Figure 5. User-centric context-awareness model integrating the specifications for the interaction with interactive tabletops, collaboration and the distribution 
From a Platform point of view (Figure 6), an attribute was added making it possible to know if the platform is multiUser or not. In order to detect inconsistencies relating to the position of the user (criteria Location, attribute position), an attribute making it possible to know the height of the platform was added. One of the interactive tabletop's characteristics is also the capacity to recognize or interact with a set of objects. We distinguish two object types: virtual objects (which are generally video-projected or displayed) and tangible objects (physical objects placed on the table). From a general point of view, the tangible objects are equipped with tags. These tags can be of a different type: bar-codes, RFID, etc., often stuck under objects so as to enable their identification. According to the capture system, it is possible to vary the number of tags stuck under the object. Thus with three tags stuck under an object, it is possible, for example, to (re)form the shape of the object using software or to detect the direction of rotation of the object (e.g. in the case of RFID technology). The RFID Technology makes it possible to store information directly in the object. Thus the object has a memory enabling it to be completely independent from the table. In the case of virtual objects, it is a videoprojector which is mainly used (it is the case with the first version of TangiSense). These platforms also evolve as regards the work surface and depend on the capture system. Finally, certain platforms can also carry an Artificial Intelligence element which can be centralized or distributed (e.g. TangiSense). A difficulty about the distribution is to connect many platforms, particularly when they have heterogenous characteristics: UI adaptation may bring promising solutions [11]. 


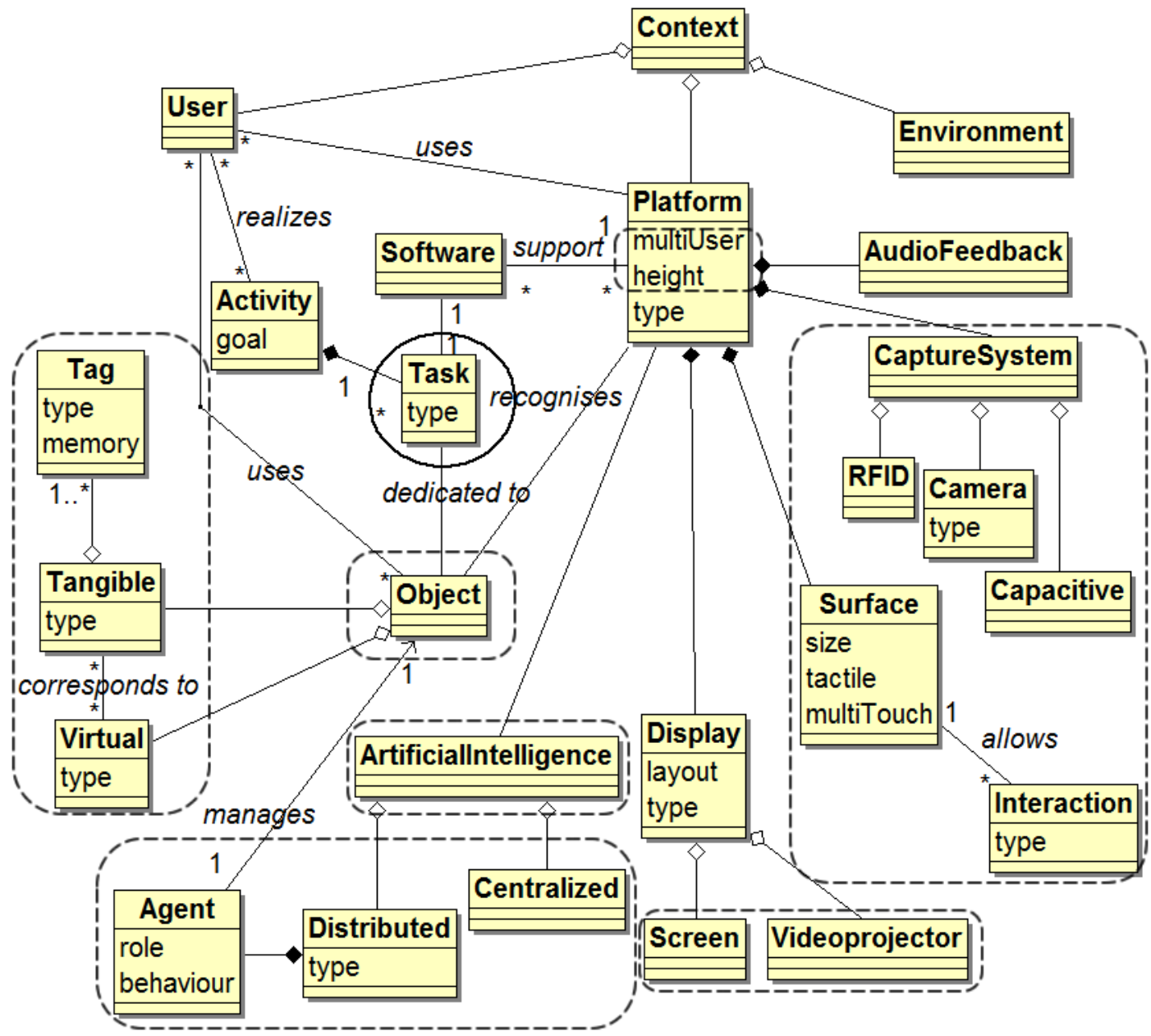

Figure 6. Platform-centric context-awareness model integrating the specifications for the interaction with interactive tabletops, collaboration and the distribution

Concerning the Environment (Figure 7), a criterion which was added relates to the collective classification of the environment: either (1) the users use the common part of the interactive tabletop, the type of workspace is then common; or (2) they use different parts of the tabletop, each one having their own workspace, in this case the type of workspace is individual [12]. 


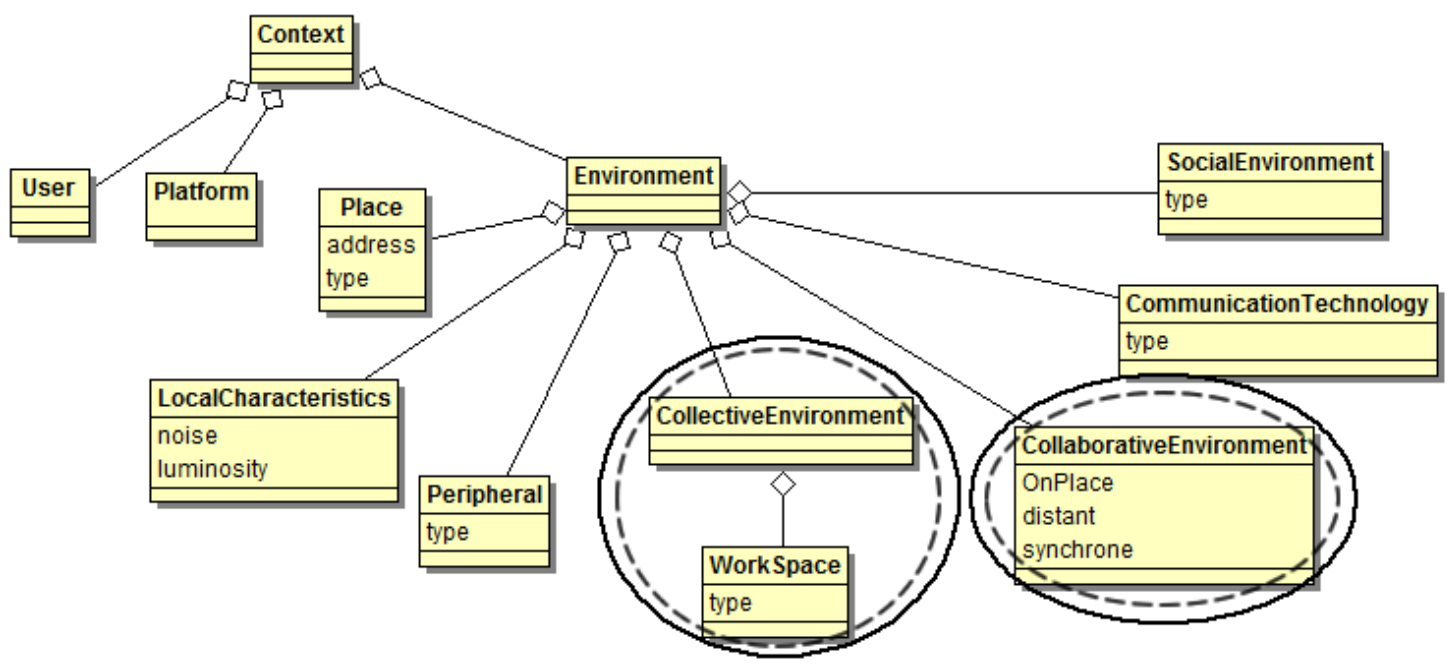

Figure 7. Environment-centric context-awareness model integrating the specifications for the interaction with interactive tabletops, collaboration and the distribution

In order to take the collaboration into account, a collaborative environment criterion was added to the Environment characteristics. Indeed, this is the environment conditions which will possibly lead the users to collaborate. This collaborative environment can be distinguished through two characteristics which will influence the interactions. Either the users collaborate by using the table (meaning a single table), in this case the collaboration is considered to be on site; or the collaboration is done on several distant platforms (the users use the table and at least one other distant support such as another table and/or another platform); in this case the environment is one of remote collaboration. The method of collaboration must be also added to the environment in order to know if collaboration is synchronous or asynchronous.

The next section aims to introduce a simulation to show our proposition and models in real context situations. 


\section{SIMULATION}

The scenario involves a child working on an amusing activity on a first interactive tabletop: Ricardo performs one or several school exercises. In particular, he is currently using the "learning and recognition of colors" application.

This application intended to teach the recognition and learning of colors (only red, yellow, blue and green) to children (aged from 2 to 5 according to the level of difficulty). The scenario is based on the French teaching syllabus for nursery schools. We asked a teacher to imagine one or more scenarios using an interactive tabletop and a set of objects without giving any limits or constraints. The teacher proposed a simple application in which the children have to move a set of objects which have "lost their color" into the suitably colored frame (i.e. a "black and white" bee should be placed inside a yellow frame) [14].

Meanwhile, his parents, Renato and Sofia, interact in another room around a second interactive tabletop (used with another goal, such as family records). The human-machine interface is different on both platforms in this first context. The child may at various times request assistance (remote collaboration) from his parents. They must be based on a common support to facilitate collaboration (e.g. direct or indirect advice to be provided on the color of certain vegetables): the humanmachine interface must be distributed on the two tabletops in this second context.

An illustration is provided in Figure 8. Several attributes of the context have changed, leading to the adaptation of the distributed interaction. 


\section{Context \#1}

- Users: Ricardo (4 years old ; child of Renato and Sofia), Renato ( 40 y/o, husband of Sofia, parent of Ricardo), Sofia (35 y/o, wife of Renato, parent of Ricardo)

Platforms: table1, table2

- Ricardo performs: "learning and recognition of colors" task (individual task)

- Renato and Sofia perform: "family records" task (collaborative task)

Environment: non collaborative, remote

Context \#2
- Users: no change
- Platforms: no change
- Ricardo performs: "learning and
recognition of colors" task (collaborative
task)
- Renato and Sofia perform: "learning and
recognition of colors" (collaborative
task) Environment: collaborative, remote

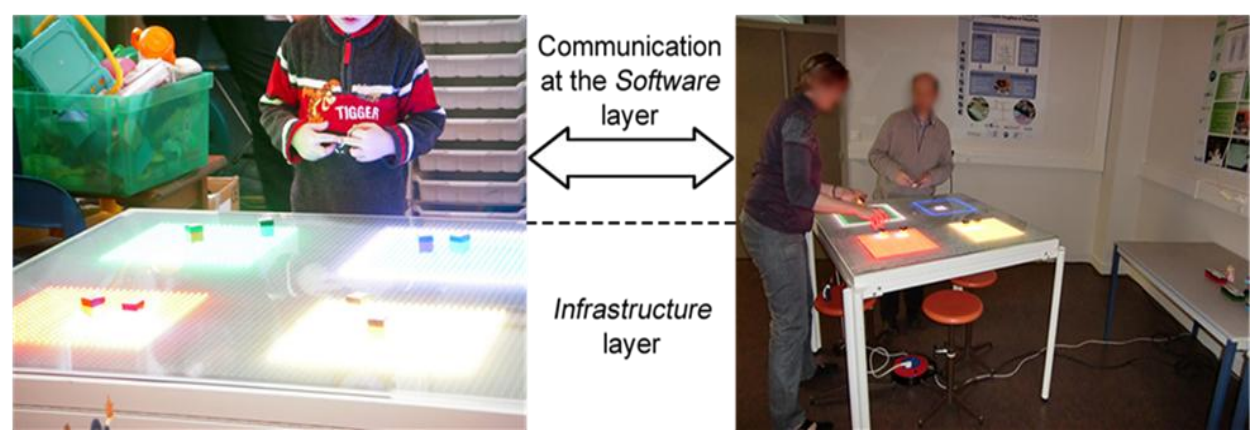

Figure 8. Illustration of the users in remote collaboration (context \#2)

Such situations are under study and development. Different evaluations are also planned 


\section{CONCLUSION \& PROSPECTS}

This chapter has presented the TangiSense tabletop and its software architecture. This architecture allows UI distribution between different tabletops and surfaces in general. This distribution is possible by integrating the intelligence of the distribution in the agents of a multi-agent system (developed with JADE [1]). Then a global context model has been described; it has been extended by taking the specificities of tabletops into account. The context model proposed in this chapter considers UI distribution on surfaces.

Our research perspectives are the following: to propose a set of adaptation mechanisms integrated into the multi-agent systems, based on the context model proposed; to propose explicit relations between the context model and usability criteria; to validate progressively the context model in various experiments, including remote collaboration.

Acknowledgments This research work was partially financed by the "Ministère de l'Education Nationale, de la Recherche et de la Technologie", the "région Nord Pas de Calais", the "Centre National de la Recherche Scientifique", the FEDER, CISIT, and especially the "Agence Nationale de la Recherche" (ANR TTT and IMAGIT projects ANR 2010 CORD 01701). The authors thank also Yoann Lebrun, Emmanuel Adam and René Mandiau for their contribution in this research.

\section{References}

[1] Bellifemine, F., Poggi, A., Rimassa, G. Developing multi-agent systems with a FIPAcompliant agent framework. Software Practice and Experience 31 (2), 103-128, 2001.

[2] Benett, P., Toru, S., Tutte-Scali, L. Blip-Tronic 3000, 2005. $\mathrm{http}: / /$ www.petecube.com/bliptronic3000.

[3] Calvary, G., Demeure, A., Coutaz, J., and Dâassi, O. Adaptation des Interfaces HommeMachine à leur contexte d'usage. Revue d'intelligence artificielle 18, 4 (2004), 577-606.

[4] Dietz, P., and Leigh, D. DiamondTouch: A MultiUser Touch Technology. In Proc. of UIST '01, ACM Press (Orlando, Florida, 2001), 219-226.

[5] Gallud J.A., Tesoriero R., Penichet V.M.R. (Eds.). Distributed User Interfaces, Designing Interfaces for the Distributed Ecosystem, Springer, 2011, ISBN 978-1-4471-2270-8.

[6] Garbay, C., Badeig, F., and Caelen, J. Normative Multi-agent Approach to Support Collaborative Work in Distributed Tangible Environments. In Proc. of CSCW'12 (Seattle, Washington, 2012).

[7] Grolaux, D., Vanderdonckt, J., and Van Roy, P. Attach Me, Detach Me, Assemble Me Like You Work. In Human-Computer Interaction INTERACT 2005, M. Costabile and F. Paterno, Eds., vol. 3585. Springer Berlin / Heidelberg, 2005, 198-212. 
[8] How does pixelsense work? [Online]. Available: http://www.microsoft.com/enus/pixelsense/pixelsense.aspx

[9] http://www.microsoft.com/surface/, 2011.

[10] Jordà, S., Kaltenbrunner, M., Geiger, G., and Alonso, M. The reacTable: a tangible tabletop musical instrument and collaborative workbench. In Proc. SIGGRAPH '06, ACM (NY, USA, 2006), 91.

[11] Kubicki S., Lebrun Y., Lepreux S., Adam E., Kolski C., Mandiau R. Simulation in Contexts Involving an Interactive Table and Tangible Objects. Simulation Modelling Practice and Theory, 31, (2013), pp. 116-131.

[12] Kubicki S., Lepreux S., Kolski C. RFID-driven situation awareness on TangiSense, a table interacting with tangible objects. Personal and Ubiquitous Computing, 16 (8), 2011, pp. 1079-1094.

[13] Kubicki, S. Contribution à la prise en considération du contexte dans la conception de tables interactives sous l'angle de l'IHM, application à des contextes impliquant table interactive RFID et objets tangibles. PhD thesis, Université de Valenciennes, France, 2011.

[14] Kubicki, S., Lepreux, S., and Kolski, C. Evaluation of an interactive table with tangible objects: Application with children in a classroom. In 2nd Workshop on Child Computer Interaction "UI Technologies and Educational Pedagogy", at CHI'2011 (Vancouver, Canada, 2011).

[15] Kubicki, S., Lepreux, S., Lebrun, Y., Santos, P. D., Kolski, C., and Caelen, J. New HumanComputer Interactions Using Tangible Objects: Application on a Digital Tabletop with RFID Technology. In Human-Computer Interaction, J. A. Jacko, Ed., LNCS 5612, Springer (2009), 446-455.

[16] Lebrun Y., Adam E., Kubicki S., Mandiau R. A Multi-agent System Approach for Interactive Table Using RFID. Y. Demazeau, F. Dignum, J-M Corchado \& J-B Perez, 8th Inter. Conf. on Practical Applications of Agents and Multi-Agent Systems (PAAMS 2010), Springer, Advances in Intelligent and Soft-Computing, Advances in Practical Applications of Agents and Multiagent Systems, Vol. 70, pp. 125-134, april 2010, ISBN 978-3-642$12383-2$

[17] Lepreux S., Kubicki S., Kolski C., Caelen J. From Centralized interactive tabletops to Distributed surfaces: the Tangiget concept. International Journal of Human-Computer Interaction, 28, (2012), pp. 709-721.

[18] Lepreux, S., Kubicki, S., Kolski, C., and Caelen, J. A step towards the distribution of tangible and virtual objects. In Distributed User Interfaces, J. A. Gallud, R. Tesoriero, and V. R. Penichet, Eds., Springer (2011), 133-143. ISBN: 978-1-4471-2270-8.

[19] Pangaro, G., Maynes-Aminzade, D., and Ishii, H. The actuated workbench: computercontrolled actuation in tabletop tangible interfaces. In Proc. of UIST '02, ACM (2002), 181-190.

[20] Schilit, B., Adams, N., and Want, R. Context-Aware Computing Applications. In WMCSA'94: Workshop on Mobile Computing Systems and Applications, IEEE Press (Santa Cruz, CA, 1994), 85-90.

[21] Tesoriero, R., Lozano, M.D. Distributed User Interfaces: Applications and Challenges. International Journal of Human-Computer Interaction, Volume 28, Issue 11 (2012), 697-699.

[22] Vanderdonckt, J. Distributed user interfaces: How to distribute user interface elements across users, platforms, and environments. Keynote address, In Proceedings of the International Conference on Interaccion, September, 2010. 
[23] Weiss, M., Schwarz, F., Jakubowski, S., Borchers, J., Madgets: actuating widgets on interactive tabletops, in: UIST '10: 23nd Annual ACM Symposium on User Interface Software and Technology, New York, USA, 2010, pp. 293-302.

[24] Yamashita, N., Kuzuoka, H., Hirata, K., Aoyagi, S., and Shirai, Y. Supporting fluid tabletop collaboration across distances. In Proc. of CHI '11, ACM (Vancouver, Canada, 2011), 2827-2836.

[25] Yang, S., Lu, Y., Gupta, S., Cao, Y. Does Context Matter? The Impact of Use Context on Mobile Internet Adoption. International Journal of Human-Computer Interaction, (2012), pp. 530-541. 